\title{
An estimation of conditions inside construction works during a fire with the use of Computational Fluid Dynamics
}

\author{
G. SZTARBAŁA* \\ Building Research Institute, Fire Research Department, 21 Ksawerów St., 02-656 Warsaw, Poland
}

\begin{abstract}
The aim of this paper is to present the application of Computational Fluid Dynamics (CFD) to the assessment of conditions inside construction works during a fire. The CFD method is now commonly used to support the design process of fire safety in construction works. This method is very useful at the preliminary stage of design because it is possible to check the internal environment during a fire and evaluate whether requirements of fire safety are met.
\end{abstract}

Key words: Computational Fluid Dynamics (CFD), fire, buildings, ventilation systems.

\section{Introduction}

Fire is the uncontrolled combustion of flammable materials within an area, which results in change of internal environment of construction works. This change causes the fire to have a direct influence on people and to impact the structure. Both of these interactions constitute fire safety in buildings as stated in European Communities Council Directive 89/106/EEC [1]. The requirements are to provide an adequate level of safety, reflected in national technical codes, according to which the building and equipment associated with it should be designed and constructed in such a way that in case of fire:

a) the load-bearing capacity of the construction is assured for a specific period of time,

b) the spread of fire and fire gases in the building is limited,

c) the spread of the fire to neighbouring construction works is limited,

d) evacuation is possible,

and the safety of rescue teams is also taken into account.

There are two broad standards for design methods associated with fire safety in construction works: prescriptive and performance.

The design recommendations in prescriptive method are mainly based on experience with identical or similar standard fire tests. For example, in this concept the volume flow rate of smoke ventilation systems depends on the cubature of the analysed space in the building and not the predicted heat release rate and smoke production of the fire. For these reasons, prescriptive designs have been evolving for many years towards performance-based designs.

In the prescriptive method the design of smoke ventilation systems based on assumptions ensures via the Required Safe Egress Time (RSET), acceptable conditions for the evacuation of people. Using the Computational Fluid Dynamics (CFD) method gives a possibility to assess development of the conditions present along of on evacuation routes over time. The time needed for acceptable conditions ensuring the smoke ventilation system (ASET - Available Safe Egress Time) is compared to the RSET. When the ASET multiplied by the safety coefficient, which is typically 1.20 , is higher than the RSET, then the fire safety conditions are met.

The first application of the CFD method is dated on 1989 [2]. Since then the CFD method has become widely used in the design of fire safety in construction works.

\section{Computational Fluid Dynamics (CFD)}

Solving problems of fluid mechanics using CFD methods is a solution that involves differential equations describing the phenomenon analysed. The basic equations that are solved for all tasks connected to the equation describing the pressure and velocity field (continuity equation) and Navier-Stokes equations. For the analysis of fire safety, especially for problems involving the spread of smoke and heat spreading, additional equations need to be solved regarding: energy and the transport of smoke.

For solving the previously presented set of differential equations describing the phenomena analysed in fluid mechanics, the following methods are used: finite difference method (FM), the finite element method (FEM) and the finite volume method (FVM). The most commonly used method in fire safety problems is the FVM, which are presented in this paper. A detailed description of FVM can be found in [3-8].

In order to solve the set of equations that describe the phenomenon analysed, it is necessary to carry out the discretization of the area of interest using a numerical grid divided into finite numbers of control volumes. In each of the control volumes equations are solved describing the analysed problem. Depending on the method of solution, the velocity is determined first, and then on the basis of the velocity the pressure and other parameters are determined (segregated method) or - as in the case of the coupled method - the ve-

\footnotetext{
*e-mail: g.sztarbala@itb.pl
} 
locity and pressure are determined first, and then the values of other parameters are calculated.

The results of calculations can be presented in the form of the distribution of the velocity field, pressure field and scalar size distributions of the analysed issue. In the case of the spread of smoke, important parameters analysed are the temperature and mass concentration of the smoke, whose distributions can be determined at any moment.

Problems related to fire safety are characterized by flows with high turbulence. It is necessary to choose a method of modelling the flow. For the modelling of turbulent flows the following methods are used: Reynolds Averaged NavierStokes (RANS), Direct Navier-Stokes (DNS), Large Eddy Simulation (LES) and Discrete Vortex Methods (DVM). In fire safety the most commonly used is the RANS method using the standard $\mathrm{k}-\varepsilon$ turbulence model.

The set of differential equations describing the turbulent flow of incompressible fluid using the standard $\mathrm{k}-\varepsilon$ model consists of the following equations:

- continuity equation

$$
\frac{\partial \overline{u_{i}}}{\partial x_{i}}=0
$$

- momentum conversation equation

$$
\rho \frac{d \overline{u_{i}}}{d t}=-\frac{\partial \overline{\mathrm{p}}}{\partial x_{i}}+2 \frac{\partial}{\partial x_{\mathrm{m}}}\left[\left(\mu+\mu_{\mathrm{t}}\right) \bar{s}_{i j}\right],
$$

- turbulence kinetic energy equation

$$
\rho \frac{d k}{d t}=\frac{\partial}{\partial x_{\mathrm{m}}}\left[\left(\mu+\frac{\mu_{\mathrm{t}}}{\sigma_{k}}\right) \frac{\partial k}{\partial x_{m}}\right]+2 \mu_{\mathrm{t}} \mathrm{s}_{i j} \mathrm{~s}_{i j}-\rho \varepsilon,
$$

- dissipation of turbulence kinetic energy equation

$$
\begin{gathered}
\rho \frac{d \varepsilon}{d t}=\frac{\partial}{\partial x_{\mathrm{m}}}\left[\left(\mu+\frac{\mu_{\mathrm{t}}}{\sigma_{\varepsilon}}\right) \frac{\partial \varepsilon}{\partial x_{m}}\right] \\
+2 \mathrm{C}_{\varepsilon 1} \mu_{\mathrm{t}} \mathrm{s}_{i j} \mathrm{~s}_{i j} \frac{\varepsilon}{\mathrm{k}}-\rho C_{\varepsilon 2} \frac{\varepsilon^{2}}{k},
\end{gathered}
$$

- turbulent viscosity equation

$$
\mu_{\mathrm{t}}=\rho \mathrm{C}_{\mu} \frac{\mathrm{k}^{2}}{\varepsilon}
$$

where: $u_{i}$ - time-averaged value of the velocity vector components, $\overline{\mathrm{p}}$ - time-averaged value of the pressure, $\mu$ - dynamics viscosity, $\mu_{\mathrm{t}}$ - turbulent dynamics viscosity, $\mathrm{s}_{i j}$ - rate of deformation tensor, $k$ - turbulence kinetic energy, $\rho$ - density of fluid, $\varepsilon$ - dissipation of turbulence kinetic energy, $\sigma_{k}$ - Schmidt number for the turbulence kinetic energy, $\sigma_{\varepsilon}-$ Schmidt number for the dissipation of turbulence kinetic energy, $C_{\varepsilon 1}, C_{\varepsilon 2}, C_{\mu}$ - coefficient of standard k- $\varepsilon$ turbulence model.

To solve the presented set of equation it is necessary to define the correct initial and boundary conditions.

The modelling of a fire's growth and the spread of its smoke and heat in construction works requires a definition of the source of fire for the CFD model. There are two main methods, i.e. the volumetric heat and smoke source model, or a description of the chemical reaction that causes the combustion process.
Chemical reactions are ignored in the volumetric model of the combustion. The heat and smoke are released from the assumed volume. The heat release rate (HRR) and the smoke are released in accordance with previously adopted fire curves (see Fig. 1). Smoke production depends on the momentum of the total HRR, the effective heat of combustion of the fuel, and the soot yield.

Therefore the rate of smoke production can be defined as follows:

$$
m_{\text {smoke }}=y_{\text {soot }} \frac{\mathrm{Q}}{\Delta \mathrm{H}_{\mathrm{c}}^{\mathrm{eff}}} \text {, }
$$

where $m_{\text {smoke }}-$ rate of smoke generation, $\mathrm{kg} / \mathrm{s}, y_{\text {soot }}-$ soot yield, $\mathrm{kg} / \mathrm{kg}, \mathrm{Q}$ - total heat release rate, $\mathrm{kW}$ and $\Delta \mathrm{H}_{\mathrm{c}}^{\mathrm{eff}}-$ effective heat of combustion of the fuel, $\mathrm{kJ} / \mathrm{kg}$.

In this approach, the smoke is modelled as an ideal gas, and has the same properties as air with the exception of its heat capacity, which is taken to be fixed at $1.00 \mathrm{~kJ} / \mathrm{kg}$.

Models using a description of the chemical reaction causing the combustion process take a one step combustion reaction in accordance with a pre-defined equation [9] and [10], or multi-stage chemical reactions whose stoichiometry and kinetics depend on the fuel and oxygen concentrations present [11].

The volumetric model of the heat and smoke source is widely used in fire safety for construction works for wellventilated fires [12-17].

Models using a description of the source of fire as a chemical reaction are still being developed and require much more research and verification. Currently they are used for studies on fire when the combustion kinetics is well known.

The numerical calculations for the spread of smoke and heat beyond the definition of the fire source model require a complete system of differential equations describing the flow of an incompressible turbulent fluid, using the following equations:

- energy balance equation,

$$
\begin{gathered}
\frac{\partial}{\partial t}(\rho E)+\frac{\partial}{\partial x_{i}}\left[(\rho E+p) u_{i}\right] \\
=\frac{\partial}{\partial x_{j}}\left[\left(k_{t c}+k_{t, t c}\right) \frac{\partial T}{x_{j}}+\left(\bar{\tau}_{i j}+\bar{\tau}_{i j}^{*}\right) u_{i}\right]+S_{h},
\end{gathered}
$$

where $E$ is the total energy dependence described, $k_{t c}$ - thermal conductivity, $k_{t, t c}$ - turbulent thermal conductivity, $S_{h}$ - source term, $\bar{\tau}_{i j}$ and $\bar{\tau}_{i j}^{*}$ are the stresses occurring in the fluid:

$$
\begin{gathered}
\bar{\tau}_{i j}=\mu\left(\frac{\partial u_{j}}{\partial x_{i}}+\frac{\partial u_{i}}{\partial x_{j}}-\frac{2}{3} \frac{\partial u_{i}}{\partial x_{i}} \delta_{i j}\right), \\
\bar{\tau}_{i j}^{*}=-\rho \overline{u_{i}^{\prime} u_{m}^{\prime}}
\end{gathered}
$$

- smoke transport equation,

$$
\begin{gathered}
\frac{\partial}{\partial t}(\rho Y)+\frac{\partial}{\partial x_{j}}\left(\rho u_{j} Y\right)=u_{i} \frac{\partial p}{\partial x_{i}} \\
+2 \mu_{t} \mu_{\mathrm{t}} \mathrm{s}_{i j} \mathrm{~s}_{i j}+\frac{\partial}{\partial x_{i}}\left[\left(D_{c}+\frac{\mu_{t}}{S c_{t}}\right) \frac{\partial Y}{\partial x_{i}}\right]
\end{gathered}
$$


where $Y$ is the mass fraction of smoke, $D_{c}$ - diffusion coefficient and $S c_{t}-$ Schmidt number is related to the turbulent flow and the rate is 0.70 .

The source term $S_{h}$ in the equation of energy balance is taken into thermal radiation from the source of fire.

\section{Assessment criteria}

The one of the most important parts of fire safety design for a smoke ventilation system is based on the performance method and involves the assessment of the efficiency of the system. There are two important criteria for the assessment of the ASET time. One of them is the temperature of the air in the first $2.00 \mathrm{~m}$ above the floor. This temperature cannot be higher than $60^{\circ} \mathrm{C}$ for dry air; when the humidity of the air is about $100 \%$ the acceptable temperature along the escape routes should not exceed $50^{\circ} \mathrm{C}$. In Figs. 1-3 the contours of temperature distribution in an underground car park during the combustion of one passenger car are presented.

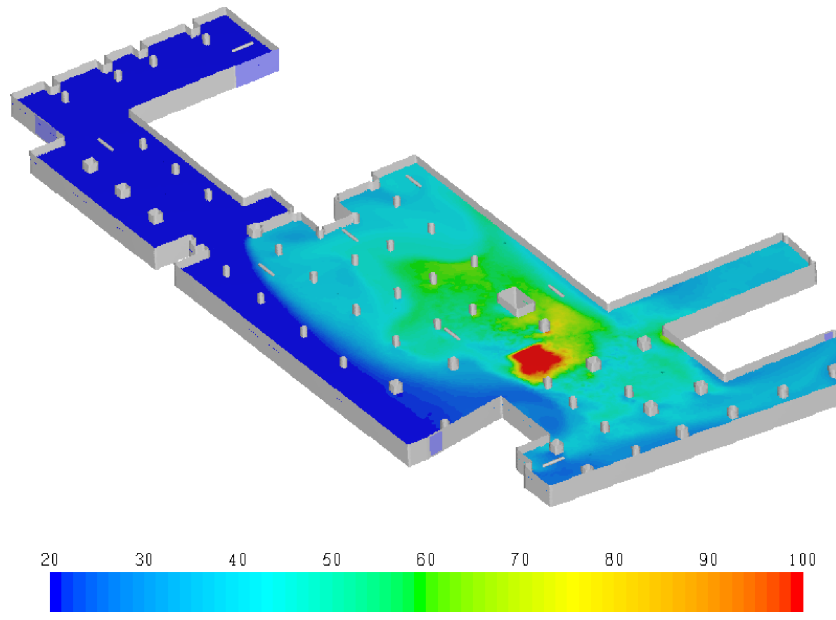

Fig. 1. Predicted temperature distribution $\left(20-100^{\circ} \mathrm{C}\right.$ and higher) at a height of $1.80 \mathrm{~m}$ above the floor at 5 minutes after the fire starts

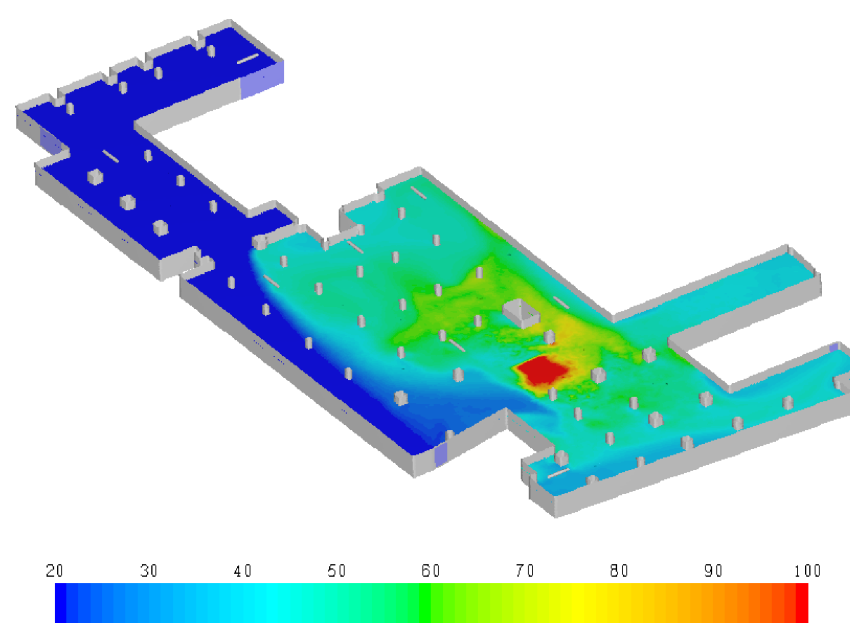

Fig. 2. Predicted temperature distribution $\left(20-100^{\circ} \mathrm{C}\right.$ and higher) at a height of $1.80 \mathrm{~m}$ above the floor at 10 minutes after the fire starts

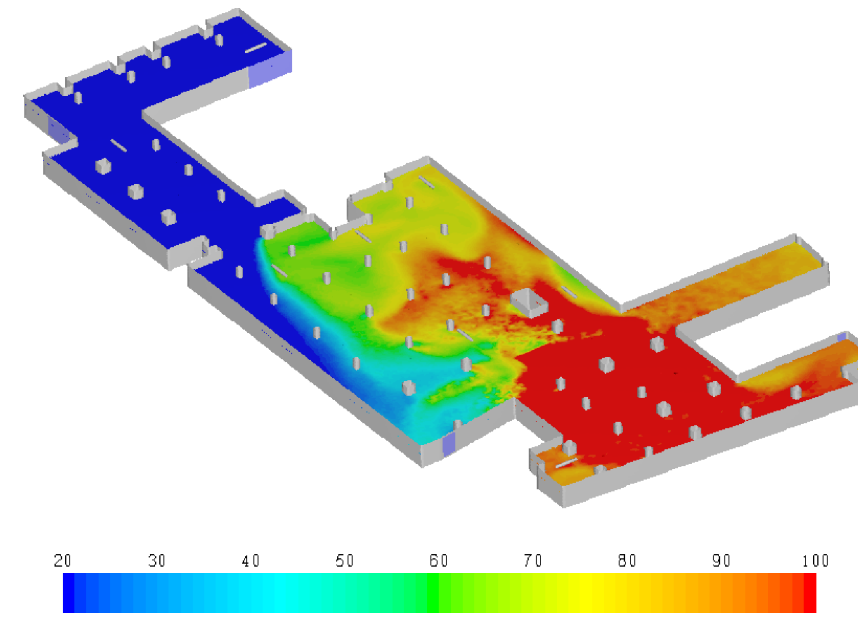

Fig. 3. Predicted temperature distribution $\left(20-100^{\circ} \mathrm{C}\right.$ and higher) at a height of $1.80 \mathrm{~m}$ above the floor at 15 minutes after the fire starts

The second criterion is the visibility of evacuations signs. All calculations of visibility rely on the theory that the visibility through a path of smoke diminishes in accordance with Bouguer's Law:

$$
I=I_{o} e^{-K L}
$$

where $I$ is the intensity of light at certain point from the source, $I_{O}$ - intensity of light at the source, $K$ - extinction coefficient and $L$ distance from the source to the point of interest.

The distance at which signs are no longer visible depends on the intensity of light emitted from the sign and the extinction coefficient of the medium. Based on the extensive experimental research of Jin [18] - the SFPE Handbook of Fire Protection Engineering [19] - recommends the following approximations for light extinction: the distance $\mathrm{S}$ is the distance at which a sign is assumed to be no longer visible. For light emitting evacuation a sign the distance $S$ is define as below:

$$
S=\frac{8}{K}
$$

and for light reflecting signs and building components that reflect light it is:

$$
S=\frac{3}{K}
$$

The extinction coefficient $K$ depends on the concentrations of the air and smoke components. We can generally assume that air has a negligible extinction coefficient over the distances involved - we do not normally expect visibility to be impaired by clean air. Therefore the extinction coefficient is purely based on the concentration of smoke. Based on the SFPE Handbook the following equation can be used:

$$
K=K_{m} \cdot \rho C_{\text {smoke }},
$$

where $K_{m}$ is the extinction coefficient per unit of mass density and $\rho C_{\text {smoke }}$ is the smoke density (the product of the smoke mass fraction and the density of the gas mixture).

The above theory is common to all approaches and is laid out in the SFPE Handbook, however, it is the implementa- 
tion of this theory that gives rise to the various methods for calculating visibility.

Historically, visibility calculations were done as hand calculations to yield an approximate average visibility. The use of averaging with CFD takes the hand calculation approach a step further. Instead of taking a room's average smoke density, an average gas density is typically calculated at a given viewing level, i.e. at a known height using the local mass contraction of smoke.

A more accurate means of determining actual optical visibility is to perform some means of ray tracing. The rays being traced would be emanated from important locations within the room, for example from a sign or from the assumed position of an occupant. Using the information stored at each computational cell in the domain the extinction of light is calculated at a number of discrete steps along the path of the ray.

Based on the regulations stated in Eqs. (12) and (13) the following percentages can be inferred as the limits of visibility for this approach:

- for light reflecting signs

$$
\frac{I}{I_{o}}=5 \%
$$

- for light emitting signs

$$
\frac{I}{I_{o}}=0.05 \%
$$

This approach makes use of all of the available information, whereas averaging techniques do not. As with the other methods the calculation is based on the theory of light extinction and the limits are based on the recommendations of the SFPE Handbook. However in this approach the full threedimensional variation in smoke concentration is taken into account.

In Figs. 4-6 the predicted visibility using the local mass concentration of smoke at a height of $1.80 \mathrm{~m}$ above the floor are presented. The results of calculating the distances at which a sign is assumed to be no longer visible using the ray tracing method are shown in Figs. 7 and 9.

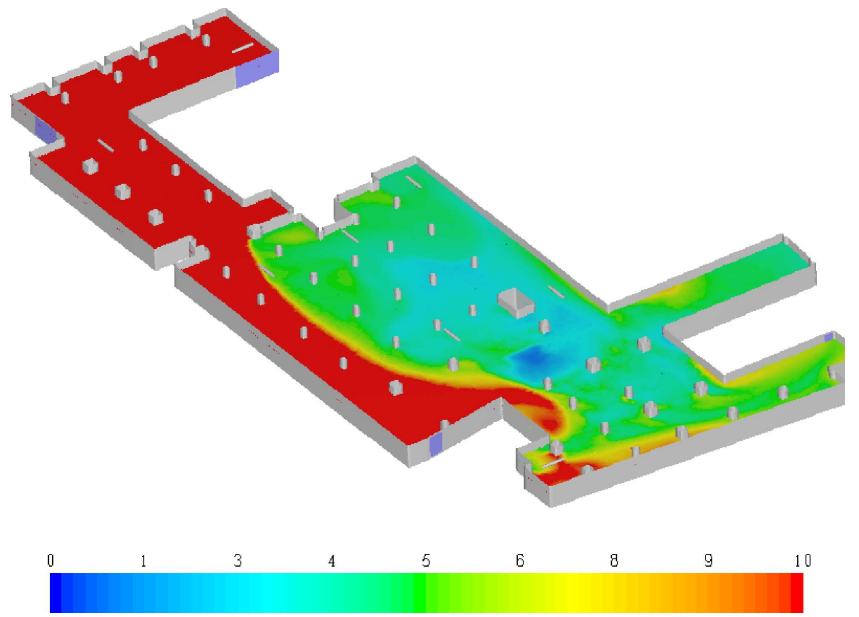

Fig. 4. Predicted visibility ( $0-10 \mathrm{~m}$ and higher) using the local mass concentration of smoke at a height of $1.80 \mathrm{~m}$ above the floor at 5 minutes after the fire starts

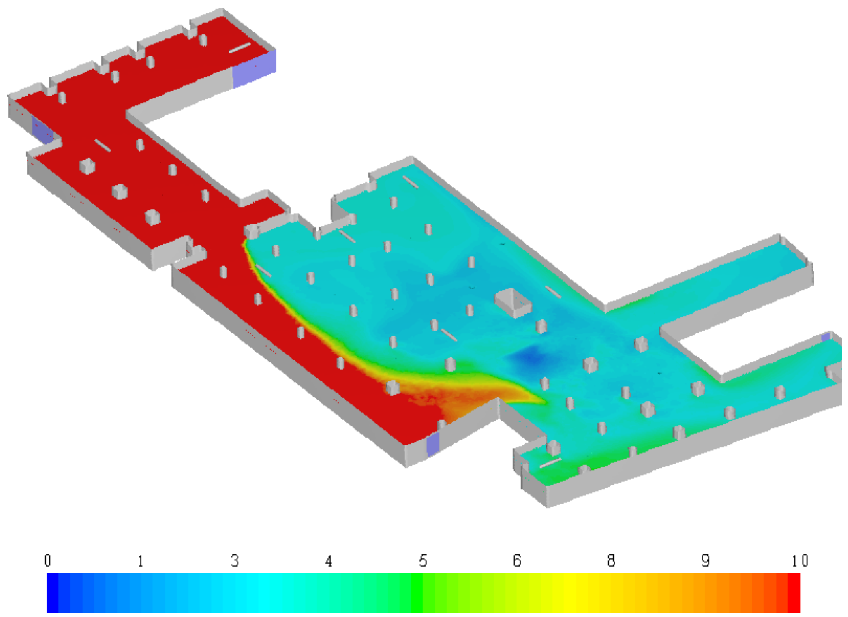

Fig. 5. Predicted visibility ( $0-10 \mathrm{~m}$ and higher) using the local mass concentration of smoke at a height of $1.80 \mathrm{~m}$ above the floor at 10 minutes after the fire starts

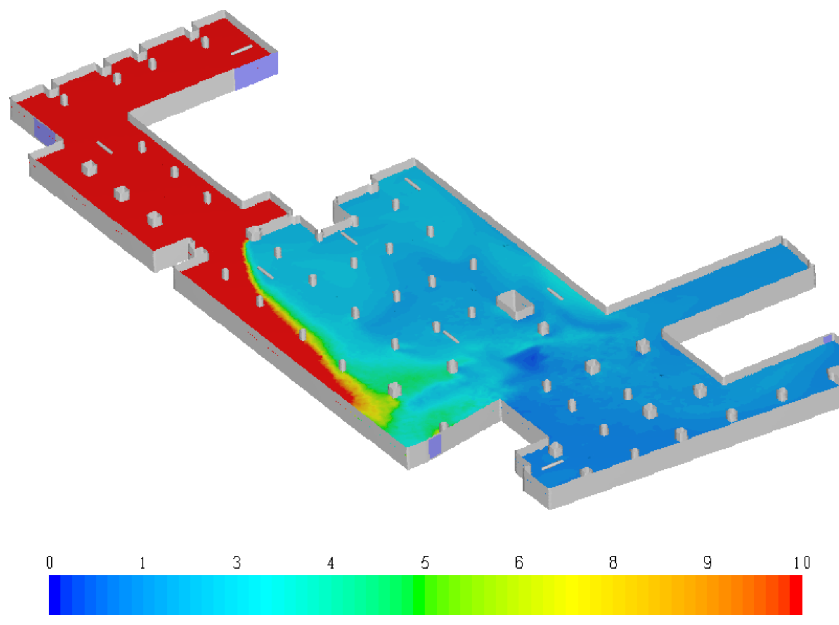

Fig. 6. Predicted visibility ( $0-10 \mathrm{~m}$ and higher) using the local mass concentration of smoke at a height of $1.80 \mathrm{~m}$ above the floor at 15 minutes after the fire starts
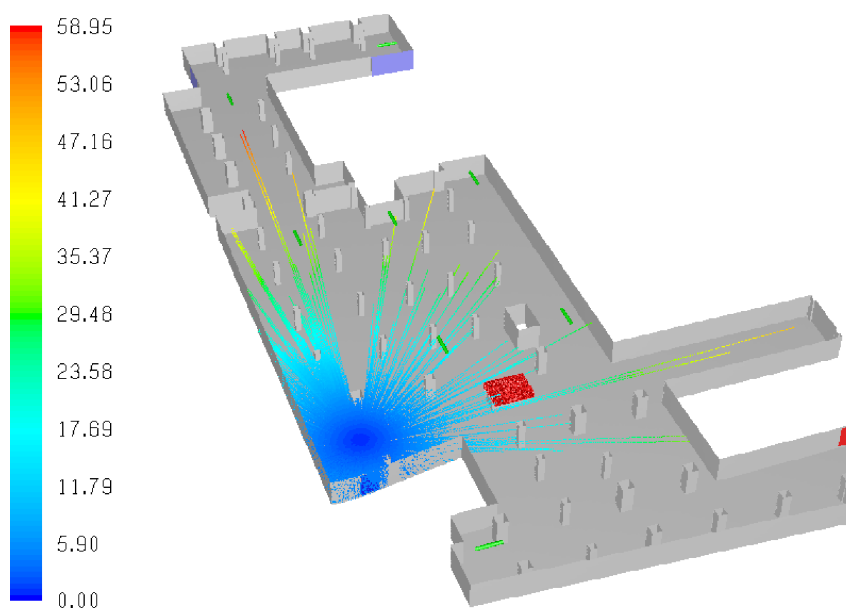

Fig. 7. Predicted distances (m) at which a sign is assumed to be no longer visible using the ray tracing method from location I 

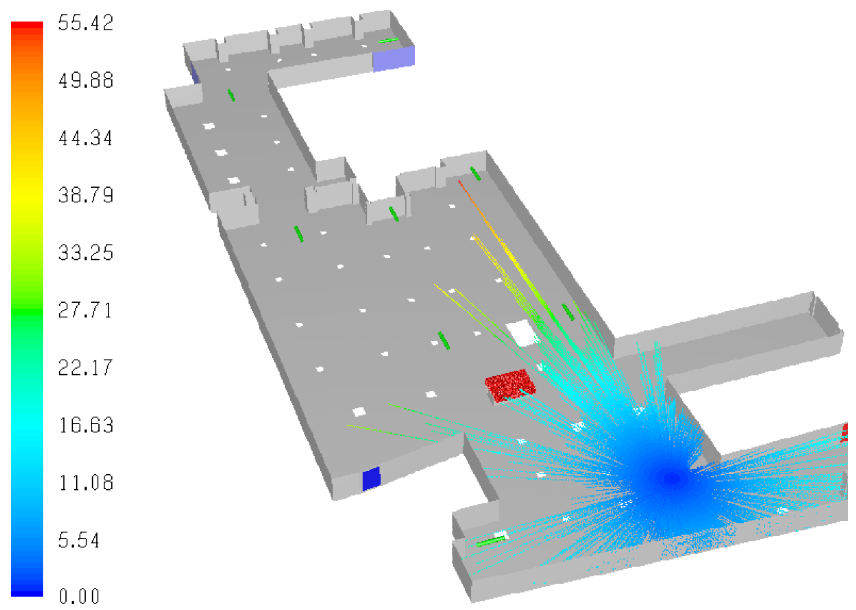

Fig. 8. Predicted distances (m)at which a sign is assumed to be no longer visible using the ray tracing method from location II
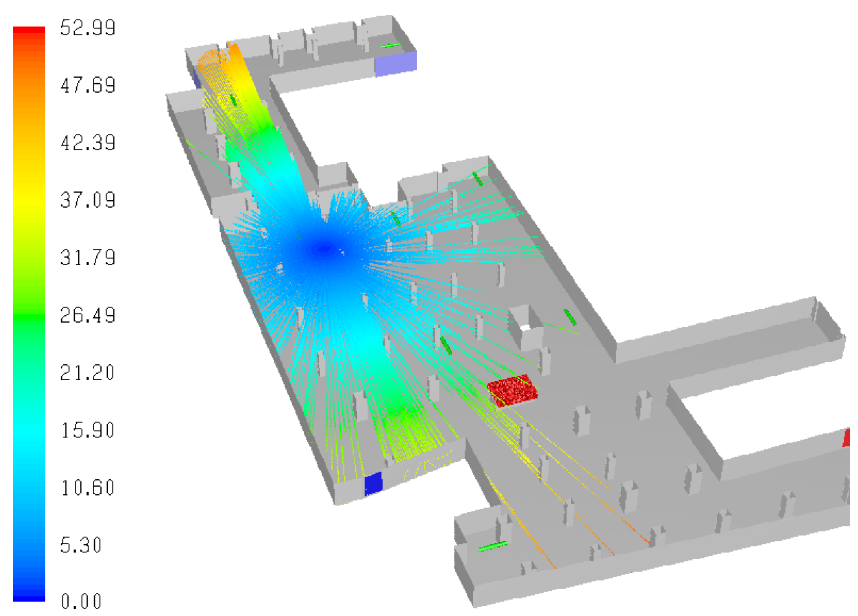

Fig. 9. Predicted distances at which a sign is assumed to be no longer visible using the ray tracing method from location III

\section{Application of CFD methods}

The Fire Research Department of the Building Research Institute (ITB) has been researching the applications of CFD methods as a tool for analysing the spread of fire, smoke and heat within fire ventilation systems of differing types of construction works for over 11 years.

In Figs. 10 and 11 the predicted temperatures close to the glass roof of a shopping centre are presented as an example. The designers and fire experts have been supported by these results in defining the fire resistance class of the roof glass.

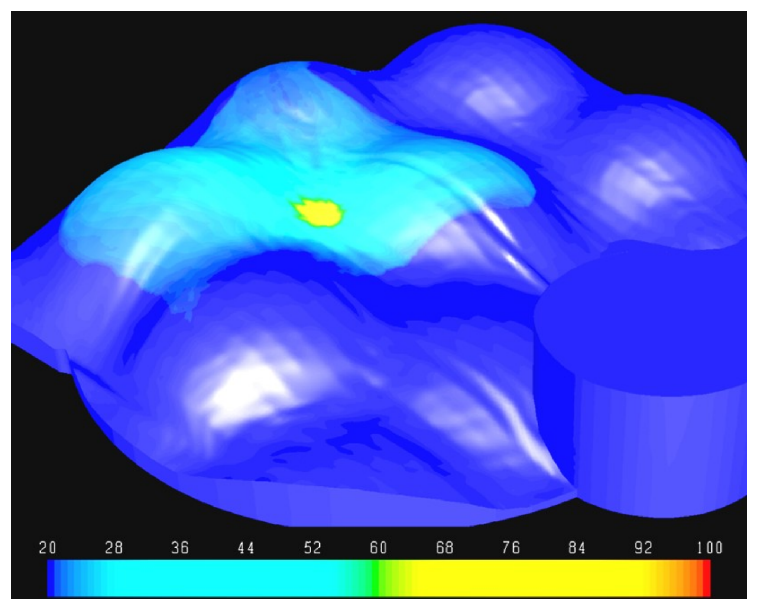

Fig. 10. Predicted temperature distribution $\left(20-100^{\circ} \mathrm{C}\right.$ and higher) close to the glass roof of a shopping centre at 5 minutes after the fire starts

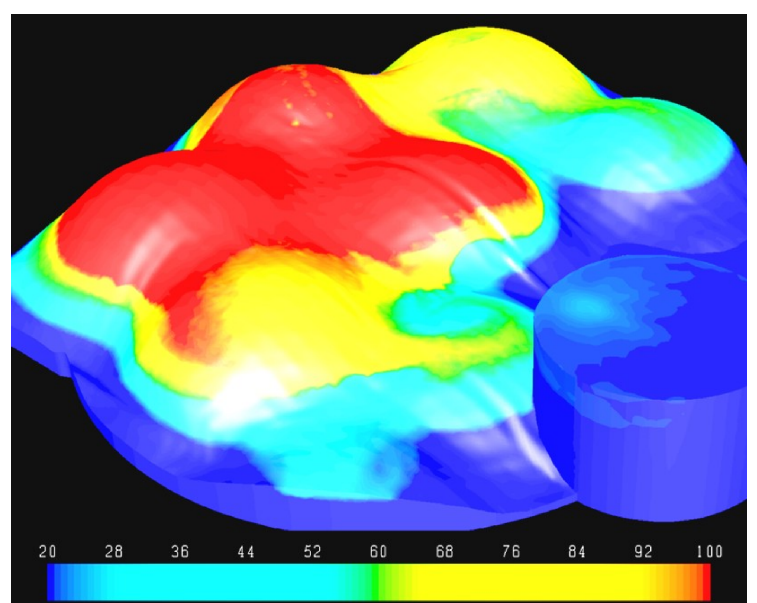

Fig. 11. Predicted temperature distribution $\left(20-100^{\circ} \mathrm{C}\right.$ and higher $)$ close to the glass roof of a shopping centre at 15 minutes after the fire starts

\section{Conclusions}

The increasing requirements for fire safety for construction projects, including ventilation systems, necessitate the use of CFD methods to analyse spread of smoke and heat in buildings. The CFD applications allow us during the design phase to compare many different kinds of fire scenarios in a relatively short time and to choose those most appropriate to protect people and their property. In comparison, analysing particular ventilation systems of existing constructions in a full scale would be very expensive and time-consuming.

Almost all new construction projects such as car parks, shopping centres, tunnels, and airport terminals - are analysed using CFD applications, which allows us to foresee the manner in which smoke and heat spread. The use of these methods has led to the improvement of fire safety systems in buildings. 


\section{REFERENCES}

[1] The Council of the European Communitties, Council Directive 89/106/EEC of 21 December 1988 on the approximation of laws, regulations and administrative provisions of the Member States relating to construction products.

[2] G. Cox, R. Chitty, and S. Kumar, "Fire modelling and the King's Cross fire investigation", Fire Safety J. 15, 103-106 (1989).

[3] A. Flaga, E. Błazik-Borowa, and J. Podgórski, Aerodynamics of Slender Structures and Bar-Cable Structures, Lublin Technical University, Lublin, 2004, (in Polish).

[4] S.V. Patankar, Numerical Heat Transfer and Fluid Flow, McGraw-Hill Book Company, London, 1980.

[5] R. Gryboś, Fundamentals of Fluid Mechanics, PWN, 1998, Warszawa, (in Polish).

[6] J.H. Ferziger and M. Perić, Computational Methods for Fluid Dynamics, Springer, Berlin, 2002.

[7] T.J. Chung, Computational Fluid Dynamics, Cambridge University Press, Cambridge, 2002.

[8] Z. Kazimierski, Fundamentals of Fluid Mechanics and Computational Fluid Dynamics Methods, Lodz University of Technology, Łódź, 2004, (in Polish).

[9] D.B. Spalding, "Mixing and chemical reaction in steady state confined turbulent flames", Proc. 21st Symp. (Int.) on Combustion 1, CD-ROM (1971).

[10] B.F. Magnussen and B.H. Hjertager, "On mathemaical modelling of turbulent combustion with special emphasis on soot formation and combustion", Proc. 16th Symp. (Int.) on Combustion 1, CD-ROM (1976).
[11] N. Peters, "Laminar flamelet concepts in turbulent combustion", Proc. 21st Symp. (Int.) on Combustion 1, CD-ROM (1986).

[12] B. Karlsson and J. Quintiere, Enclosure Fire Dynamics, CRC Press, London, 2000.

[13] G. Hadijsophocleous and C. McCartney, "Guidelines for the use of cfd simulations for fire and smoke modeling", ASHRAE Trans. 111, CD-ROM (2005).

[14] H.Y. Guan and K.Y. Kwok, Computational Fluid Dynamics in Fire Engineering: Theory, Modelling and Practice, Elsevier, Oxford, 2009.

[15] G. Sztarbała, "Computational fluid dynamics as a tool of fire engineers - good practice", Proc. EuroFire 2011: 5th Eur. Conf. Fire Safety Engineering: Trends and Practical Applications 1, CD-ROM (2011).

[16] K. McGrattan and S. Miles, "Modelling enclosure fires using computational fluid dynamics (CFD)", in SFPE Handbook of Fire Protection Eng., pp. 3-229-3-246, National Fire Protection Association, Massachusetts, 2008.

[17] N. Rhodes, "CFD modelling of tunnel fires", in The Handbook of Tunnel Fire Safety, pp. 267-283, Thomas Telford, Massachusetts, 2005.

[18] T. Jin, "Visibility and human behaviour in fire", in SFPE Handbook of Fire Protection Engineering, pp. 2-42-2-53, National Fire Protection Association, Massachusetts, 2008.

[19] P.J. DiNenno, D. Drysdale, C.L. Beyler, W. Douglas Walton, R.L.P. Cluster, J.R. Hall, Jr., and J. M. Watts, Jr., SFPE Handbook of Fire Protection Engineering, National Fire Protection Association, Massachusetts, 2008. 